\title{
MINIMIZING STRENGTH CONSEQUENCES RESULTING FROM EXCAVATION OF BURIED GAS PIPELINE FOR IN-OPERATION INSULATION RENOVATIONS
}

\author{
Assoc. Prof. MSc. Roland JANČO, PhD. \\ Institute of Applied Mechanics and Mechatronics, Faculty of Mechanical Engineering, \\ Slovak University of Technology Bratislava, Slovak Republic, \\ roland.janco@stuba.sk
}

\begin{abstract}
Because of economic reasons many of the maintenance and repair activities on buried gas pipeline are performed during its operation. By excavating the earth from the sides of the pipeline in certain lengths, there is a possibility that the resulting additional bending load of the pipe will occur due to its deflection. This is caused by the additional compressive force which originates in the buried pipeline as a result of a detained strain, when the longitudinal strain in the pipeline due to service conditions (internal pressure and heating) cannot be realized. In the paper a numerical simulation (using ANSYS program) of pipeline elbow due to excavation for insulation repair and the following backfilling will be presented.
\end{abstract}

KEYWORDS: buried pipeline elbow, additional loading after filling excavation, non-compacted ground, gravel pipe bed

\section{INTRODUCTION}

Many maintenance activities and repairs of gas pipelines are carried out during their operation for economic reasons. High-pressure gas pipeline, from a strength aspect, can be considered a closed cylindrical shell with an axis represented by a $3 \mathrm{D}$ curve consisting of straight sections, large radius elbows, and small bending angle.

A pipeline buried in the earth is loaded by pressure from the transported gas, thermal expansion, gravitational forces of the pipeline and the earth over it, reaction forces between the earth and pipeline and friction forces respectively. Friction forces acting on a relatively short part of the pipeline (few hundred meters), are capable of retaining longitudinal deformation of the pipe originating from internal pressure and temperature change; as a result, considerable axial compression force originates in the pipeline. In the straight parts of the pipeline this force causes only compressive load, while in the elbows an additional bending load is created as well. The bending load is negligible since the elbows are supported by the naturally compacted earth on its sides and at the bottom. We used Tresca's hypothesis in strength assessment of the resultant multiaxial strain. In the pipeline the principal stresses are in the tangential, axial and radial directions. They are given by the equations

$$
\begin{aligned}
& \sigma_{t}=\frac{p \mathrm{~d}_{\mathrm{S}}}{2 \mathrm{~h}}, \\
& \sigma_{a}=\frac{p \mathrm{~d}_{\mathrm{S}}}{4 \mathrm{~h}}+\sigma_{N}=\frac{p \mathrm{~d}_{\mathrm{S}}}{4 \mathrm{~h}}-\left[\frac{p \mathrm{~d}_{\mathrm{S}}}{4 \mathrm{~h}}(1-2 \mu)+E \alpha \Delta T\right], \\
& \sigma_{r}=-p \cong 0,
\end{aligned}
$$

where $\mathrm{d}_{\mathrm{s}}, \mathrm{h} \quad \ldots \quad$ are the mean diameter of the pipe, and wall thickness respectively 
SCIENTIFIC PROCEEDINGS 2011, Faculty of Mechanical Engineering, STU in Bratislava Vol. 19, 2011, pp. 142-149, DOI: 10.2478/v10228-011-0023-y

$\mu, \alpha \quad \ldots \quad$ are Young's modulus, Poisson's ratio, and thermal expansion coefficient of the pipe material,

$\mathrm{p}, \Delta \mathrm{T} \quad \ldots \quad$ are operating pressure and temperature increment with respect to the reference temperature of the pipeline during its assembly.

Given that the largest principal stress is $\sigma_{1}=\sigma_{t}$ and the smallest is $\sigma_{3}=\sigma_{r}=0$ then the stress intensity is given by: $\quad \sigma_{i}=\sigma_{1}-\sigma_{3}=\sigma_{t}$.

We can conclude, that compressive force from retained axial strain does not affect the stress intensity, neither in the straight sections nor in the elbows, of buried pipeline.

If we excavate a longer part of an operational pipeline, i.e. we remove the supporting effect of the compacted earth and reactions from the bottom respectively, the loading of that section of pipeline is affected due to compressive force from retained axial strain.

A straight pipeline, which is excavated in sufficiently long lengths, can move sideways and as a result may introduces an additional bending load. In the deflected section, the compressive force slightly decreases and its decrease must be compensated by frictional forces of the earth near the edges of excavation. This problem was theoretically solved in [1], [2], [6].

If the pipeline elbow is dug underneath, a significant additional bending load originates in it, where the magnitude of the bending load is determined by the geometrical shape of the elbow and is practically independent on the pipe deflection, see [3]. If we denote $\Delta \sigma_{\mathrm{N}}$ as the axial compressive stress decrease, and $\sigma_{0, \max }$ as the stresses corresponding to the additional bending moment, than the principal stress in the axial direction will be given by:

$$
\sigma_{a}=\frac{p \mathrm{~d}_{\mathrm{S}}}{4 \mathrm{~h}}+\left(\sigma_{N}-\Delta \sigma_{N}\right) \pm \sigma_{o, \max } .
$$

Consequently the axial stress becomes the smallest on the side where the compressive bending stresses act, i.e. $\sigma_{3}=\sigma_{a}$, and the stress intensity increases.

Significant additional loading of the gas pipeline occurs when excavating for the renovation (of insulation) of convex elbow (in a valley), situated in a vertical plane. Two technological procedures of excavation, evaluated by the factor of safety at the critical place of the pipeline after renovation, are presented in this paper.

\section{STRESS-STRAIN ANALYSIS OF ELBOW AFTER ISOLATION COAT RENOVATION}

In this part we determine additional loading of the convex buried gas pipeline elbow at individual phases of insulation renovation during its operation, i.e. in the excavated state and after backfilling. We evaluate the state, when filling is done without earth compaction as well as when the load bearing gravel bed is created.

The numerical analysis was made by finite element method using the ANSYS program. For modeling the gas pipeline we used the PIPE16 element, which enables realization of overpressure in the pipe, outer unit loading along the pipeline and temperature loading as well. The compressive axial force from restrained longitudinal deformation was realized by fixing the pipe model at the ends. The CONTAC52 element was used for modeling the contact between the earth and the pipeline, which simulates compressive normal reaction force of the earth and friction force in the opposite direction to the displacement of the pipe element. The element enables us to realize a gap as well, i.e. displacement of the pipe element in the normal direction, for which contact does not occur. Numerical analysis was performed for a pipeline dimension of DN $1200\left(\mathrm{~d}_{\mathrm{S}}=1200 \mathrm{~mm}, \mathrm{~h}=\right.$ $13,6 \mathrm{~mm}$ ), where the pressure and temperature of transported gas were $\mathrm{p}=6,6 \mathrm{MPa}, \mathrm{T}=38^{\circ} \mathrm{C}$ (i.e. $\Delta \mathrm{T}=23^{\circ} \mathrm{C}$ ). Parameters of the elbow are: radius $\rho_{0}=203,6 \mathrm{~m}$, bending angle $\alpha=9^{\circ}$; the slopes of the straight sections of pipeline at both sides of the elbow are the same. We assume, that the 
SCIENTIFIC PROCEEDINGS 2011, Faculty of Mechanical Engineering, STU in Bratislava Vol. 19, 2011, pp. 142-149, DOI: 10.2478/v10228-011-0023-y

renovation of insulation was realized along the whole length of the elbow, i.e. $32 \mathrm{~m}$. The height of the earth layer covering the pipeline is $1,2 \mathrm{~m}$, see [4], [5], [6]. Two technological procedures of the earthwork during repair are evaluated in the following sections.

\section{EXCAVATION AND BACKFILLING WITHOUT COMPACTING}

Let us consider the case of an elbow, which is weakened along its whole length. On this section (between points 1 and 2 in Fig. 1) the pipeline creates a bridge with the straight sections laying on compacted ground with a normal stiffness of $\mathrm{KN}=10.10^{6} \mathrm{~N} / \mathrm{m}^{2}$ and a friction coefficient $\mathrm{f}=0,4$. The deflection curve of the pipe axis is given in Fig. 1 with a maximum value of radial displacement $u_{\max }=10,6 \mathrm{~cm}$. Due to the deflection, the axial compressive stress decreases by $\Delta \sigma_{\mathrm{N}}=$ $-20,7 \mathrm{MPa}$, related to its original value from the retained axial strain $\sigma_{\mathrm{N}}=-115,5 \mathrm{MPa}$. The corresponding additional bending moment diagram is shown in Fig.2 with a maximum stress value $\sigma_{\mathrm{o}, \max }=125 \mathrm{MPa}$ in the middle of the elbow, and $\sigma_{\mathrm{o}, \max }=123 \mathrm{MPa}$ (with opposite orientation) in the cross-sections above the load bearing bed near the edges of the excavation (points 1,2 ). In these sections (on the side of compressive bending stresses) the stress intensity values are $\sigma_{\mathrm{i}}=366 \mathrm{MPa}$, and $\sigma_{\mathrm{i}}=364 \mathrm{MPa}$, respectively; for comparison, the value of stress intensity before weakening of the elbow was only $\sigma_{\mathrm{i}}=286 \mathrm{MPa}$.

If we backfill the excavation without compacting the pipe bed after renovation, the pipe loading will worsen due to the gravitational force generated by the covering earth; this ground bed is not bearing, i.e. increasing the deflection of the pipe axis another $10 \div 15 \mathrm{~cm}$. The bed is not able to bear practically any normal loading. Maximum value of

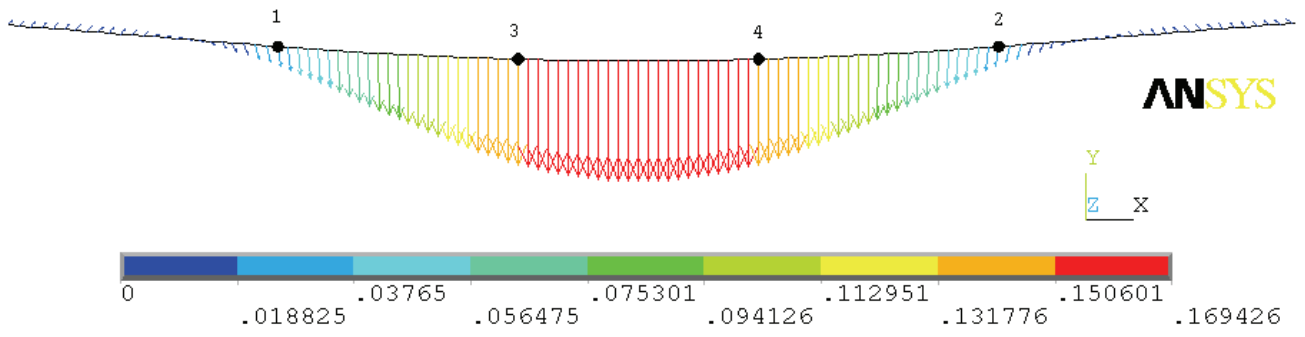

Fig. 1 Deflection diagram of pipe axis [m] at sapping elbow along the whole length

radial displacement increases to $\mathrm{u}_{\max }=16,9 \mathrm{~cm}$; due to deflection of the pipe axis, the axial compressive stress decreases by $\Delta \sigma_{\mathrm{N}}=-25,7 \mathrm{MPa}$ and in cross-sections with extreme values of bending moment the corresponding stresses will reach $\sigma_{\mathrm{o} \text {,max }}=199,9 \mathrm{MPa}$ (at the middle of the elbow) and $\sigma_{o, \max }=189,5 \mathrm{MPa}$ (near the edges of the excavation). The stress intensity diagram is shown in Fig. 3 with a maximum value of $\sigma_{i}=433 \mathrm{MPa}$. This 1,51-multiple increase of stress intensity with respect to the value before renovation, is evidently inadmissible, because in the same rate the factor of safety of the pipeline decreases.

The same result would be obtained, if the excavation and following backfilling is performed in shorter lengths and repeated several-times (e.g. twice or three-times), incidentally with some pause, too (i.e. one-two years); after some time the freely filled earth will naturally compact, and a hollow will be created under the pipeline. It is clear, that the quality of the new bearing bed created after renovation has a significant influence on the additional loading of the pipeline. 
SCIENTIFIC PROCEEDINGS 2011, Faculty of Mechanical Engineering, STU in Bratislava Vol. 19, 2011, pp. 142-149, DOI: 10.2478/v10228-011-0023-y

\section{SUCCESSIVE PIPELINE WEAKENING AND IMPLEMENTATION OF LOAD BEARING GRAVEL BED}

Because compacting the earth under the pipeline is practically impossible, the creation of a new load bearing gravel bed has to be considered. The deformation characteristic of gravel with a grain size of about $10 \mathrm{~mm}$ mixed with sand, validity for the experimental model is shown in Fig.4. In the experiment this mixture was situated in a steel pipe of inner diameter $\phi 145 \mathrm{~mm}$ and length $\mathrm{h}$ $=150 \mathrm{~mm}$ and it was compressed by a piston. We can substitute (for higher pressure) this strongly non-linear characteristic by a straight line, shifted from the coordinate system origin by an initial non-resistance displacement denoted by $\Delta$.

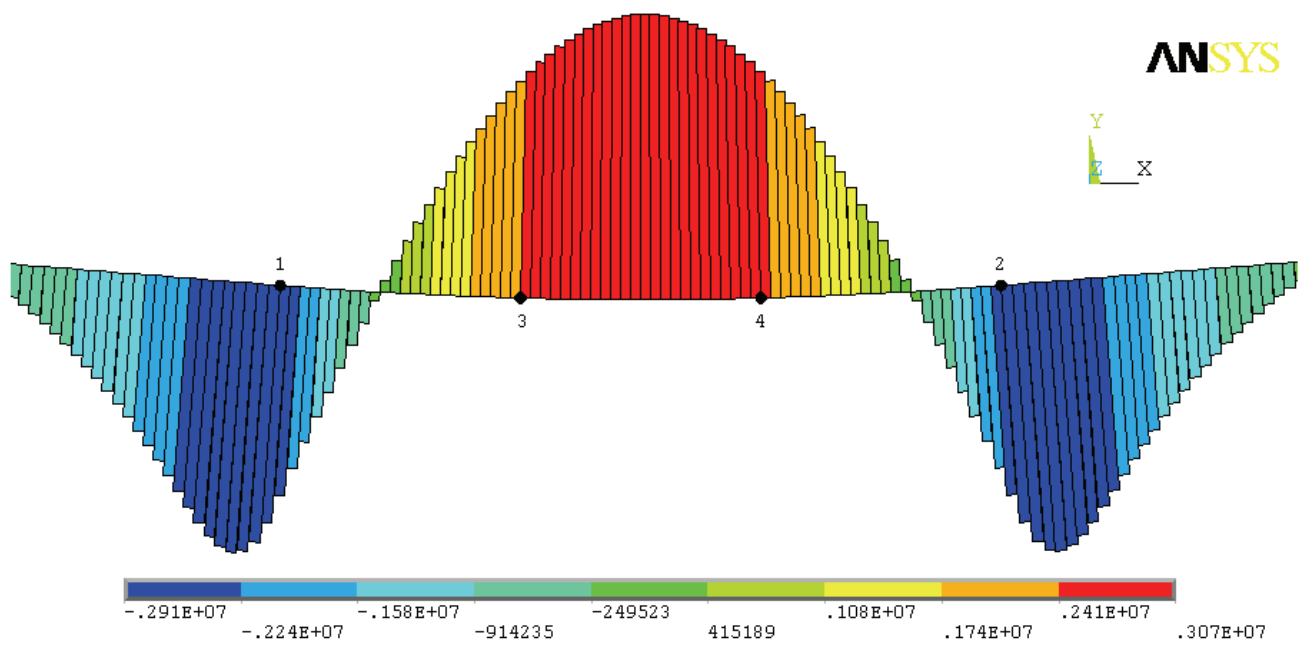

Fig. 2 Additional bending moment diagram [Nm] at weakened elbow along the whole length

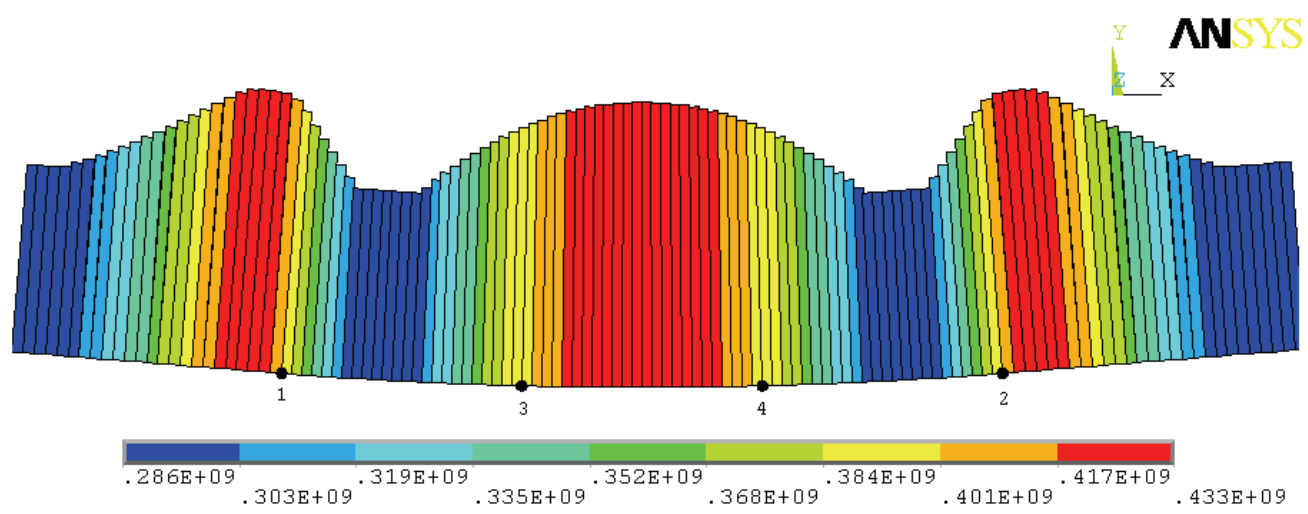

Fig. 3 Stress intensity diagram $\left[N / m^{2}\right]$ after backfilling without compacting pipe bed

In order to use the above mentioned characteristic to describe the deformation characteristics of a new load bearing bed during insulation renovation, it is necessary to ensure the deformation state of the gravel to be similar as it was in the experiment, e.g. compression in quasi-closed space. That can by done in the following way: gravel is filled up under the pipeline as long as a contact 
SCIENTIFIC PROCEEDINGS 2011, Faculty of Mechanical Engineering, STU in Bratislava Vol. 19, 2011, pp. 142-149, DOI: 10.2478/v10228-011-0023-y

with the pipe occurs in the width equal to approximately half of the pipe diameter; downwards the gravel width will increase, e.a. due to the pouring angle. This gravel layer (with a height of about $0,6 \mathrm{~m}$ ) is enclosed by a layer of compacted earth, whose top reaches at least the level of the pipe axis. Then for the deformation characteristic of gravel bed a normal stiffness $\mathrm{KP}=5.10^{6} \mathrm{~N} / \mathrm{m}^{2}$ and non-resistance displacement up to $\Delta=0,025 \mathrm{~m}$ can be used.

Let us evaluate the strength consequence of excavating a convex elbow realized by the following technological procedure:

- In the first phase the earth covering the pipeline is excavated and its sides are dug away along the whole length of the elbow, so the pipe is left lying on the compacted earth.

- In the second phase the earth is removed from under the pipe along some section of its length, e.g. along one third (see Fig. 5a, between points 1 and 3). After the insulation repair, the new load bearing gravel bed is created in the way mentioned above. Due to subsequent weakening of the pipe, it is necessary to create a retaining wall from bags filled with gravel. In the figure a non-resistance displacement $\Delta$ of gravel bed is also drawn. This procedure is repeated twice, see Fig. 5b, c. In Fig. 5b we can see, that the deflected pipeline is supported by the gravel bed part on the left to point 3 and the second third of the elbow (points 3 and 4 ), and therefore the values of radial displacement are small.

- In the third phase the pipeline elbow is burried with soil along its whole length.

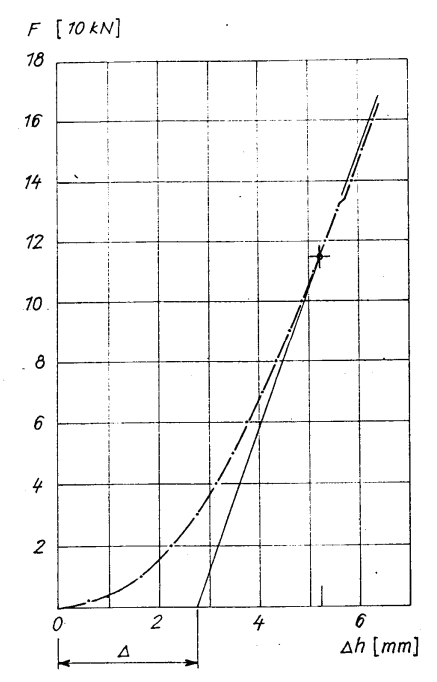

Fig. 4 Deformation characteristic of load bearing gravel bed model

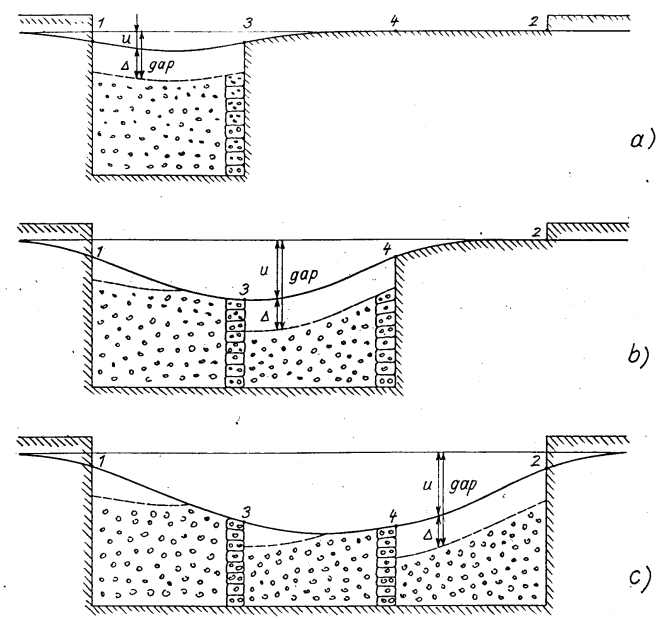

Fig. 5 Demonstration of single phases of successive pipe weakening and simultaneous creation of load bearing gravel bed

We note, that CONTAC52 elements request the measurement gap value of the original position of the pipeline elbow axis (before renovation, when pipe lays on compacted ground). For simulation of stress-strain state after renovation, the gap value in its general place given with coordinate $\mathrm{x}$ is expressed by

$$
\operatorname{gap}(x)=u_{i}(x)+\Delta
$$


SCIENTIFIC PROCEEDINGS 2011, Faculty of Mechanical Engineering, STU in Bratislava Vol. 19, 2011, pp. 142-149, DOI: 10.2478/v10228-011-0023-y

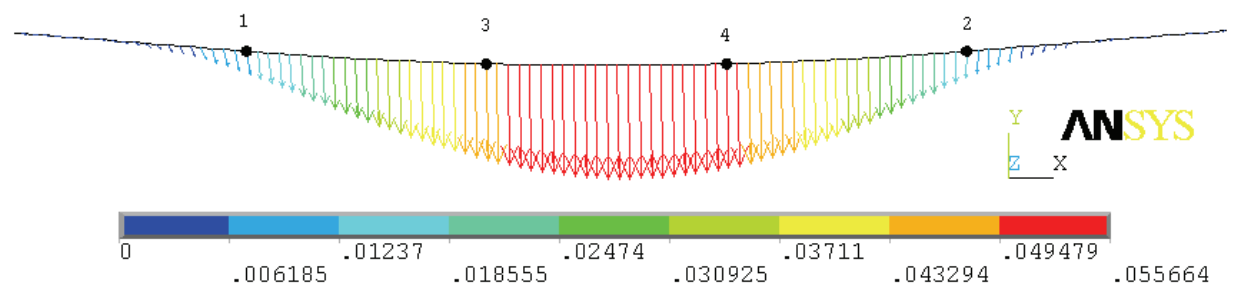

Fig. 6 Deflection diagram of pipe elbow axis [m] after repair at excavation and creation of gravel bed in three-sections

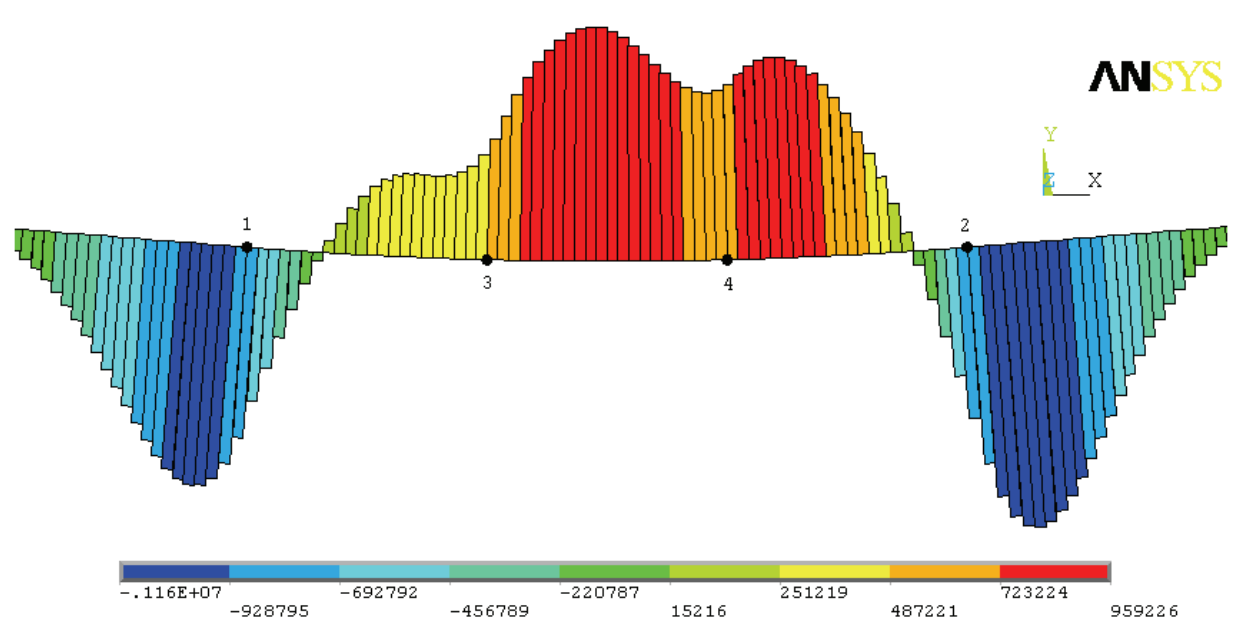

Fig. 7 Additional bending moment diagram [Nm] after repair at excavation and creation of gravel bed in three-sections

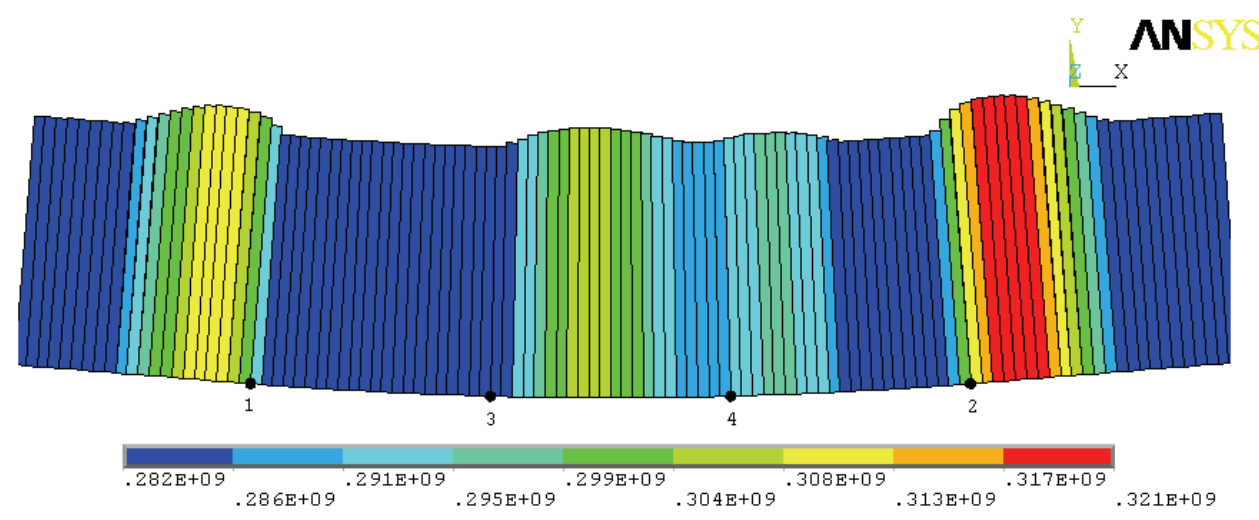

Fig. 8 Stress intensity diagram $\left[N / \mathrm{m}^{2}\right]$ after repair at excavation and implementation of the gravel bed in three sections 
SCIENTIFIC PROCEEDINGS 2011, Faculty of Mechanical Engineering, STU in Bratislava Vol. 19, 2011, pp. 142-149, DOI: 10.2478/v10228-011-0023-y

where $\mathrm{u}_{\mathrm{i}}(\mathrm{x})$ is radial displacement of the elbow axis in a general place of the same elbow part, which has just been excavation. Therefore, it was necessary to determine the deflection curve at every step of successive excavation of the pipe followed by implementation of the gravel bed.

The results of numerical stress-strain analysis of the convex elbow after renovation, realized in the above mentioned method of successive pipe excavation and simultaneous gravel bed creation in three-sections, are shown in the following figures. Fig. 6 presents the deflection curve of the pipeline axis; with a maximum value $\mathrm{u}_{\max }=5,6 \mathrm{~cm}$. Due to deflection, the axial compressive stress decreases by $\Delta \sigma_{N}=-14,4 \mathrm{MPa}$, related to its original value from retained longitudinal strain $\sigma_{\mathrm{N}}=-$ $115,4 \mathrm{MPa}$. The corresponding additional bending moment diagram is shown in Fig. 7 with a maximum stress value of $\sigma_{\mathrm{o}, \max }=75,5 \mathrm{MPa}$ in the cross-section above the load bearing bed near the edge (2) of the excavation. The diagram of stress intensity at critical points of every cross-section is given in Fig. 8. The maximum value is $\sigma_{\mathrm{i}}=321 \mathrm{MPa}$, that is 1,14-times higher than it was before renovation $\left(\sigma_{i}=282 \mathrm{MPa}\right)$. We can conclude then, that the evaluated technological procedure of gravel bed implementation is applicable and has merit.

\section{CONCLUSION}

Considering the numerical results of the stress-strain state of a buried gas pipeline after repair (at which the pipe is weakened during operation) it is necessary to create a new load bearing pipe bed when excavating. Because the earth compaction under the pipeline is practically impossible, the creation of a load bearing bed from gravel has to be considered. Using the technological procedure, in which the weakening of the pipe elbow and following gravel bearing bed implementation is performed successively in three consecutive sections), we can reduce the value of the stress intensity in critical places (by 1,14 times the value referring to the state before renovation). For comparison we used the same elbow, where backfilling after renovation was done with the non-compacted earth; the value of the stress intensity in critical place was 1,51-times higher than its original value. As the factor of safety of this pipe part decreases at the same rate, this excavation and repair method is evidently unacceptable.

\section{REFERENCES}

[1] JANČO, R.: Numerical analysis of buried gas pipeline during operatiom. Habilitation thesis, SjF STU Bratislava, 2010

[2] PODĚBRADSKÝ, J.: Change of stress-strain state of buried gas pipeline at backfill removal during operation. In: Proceedings of conference Maintenance and repair of gas pipelines, High Tatras, 2000, Paper 34, 7 p.

[3] PODĚBRADSKÝ, J., BENČA, S.: Additional loading of buried gas pipeline elbow at backfill removal during operation., In: Proceedings of conference Strojné inžinierstvo'2001, STU Bratislava, 2001, Section No. 9, p. 602-607

[4] PODĚBRADSKÝ, J., JANČO, R., BENČA, S., ELESZTŐS, P.: Resultant stress state at critical locality of a pipeline laid in hilly terrain caused by its digging off during operation., In: Technical report of SjF STU Bratislava, 2002, Part I, 44 p.

[5] JANČO, R., PODĚBRADSKÝ, J.: Numerical simulation of loading of buried gas pipeline elbow after renovation of isolation coat during operation, In: Proceedings of conference „,Applied Mechanics 2003“", Gliwice, Poland, 2003, p. 101-106

[6] JANČO, R.: FEM approach of solution of beams on elastic foundation. In NÁHLÍK, L. -A KOL. Applied Mechanics 2011 : Conference Proceedings. 13th conference. Velké 
SCIENTIFIC PROCEEDINGS 2011, Faculty of Mechanical Engineering, STU in Bratislava Vol. 19, 2011, pp. 142-149, DOI: 10.2478/v10228-011-0023-y

Bílovice, April 18-20, 2011. Brno: Academy of Sciences of the Czech Republic, 2011, s. 71-74. ISBN 978-80-87434-03-1. 